DOI: 10.17707/AgricultForest.64.1.12

Tonya GEORGIEVA, Ivanka TOROMANOVA ${ }^{1}$

\title{
FORMATION OF PANICLE BASIC ELEMENTS WITH TURKISH AND ITALIAN RICE CULTIVARS GROWN IN BULGARIA
}

\section{SUMMARY}

A two-factor field experiment was carried out in the Saedinenie region, Plovdiv municipality, Bulgaria in the period 2013 - 2015 following the split plot design with size of the reporting plot of $14 \mathrm{~m} 2$. Two Turkish (Osmanchik 97 and Gala) and four Italian cultivars (Lince, Cameo, Puma and Brio) were studied in the survey, grown on the larger plots (Factor A). Three foliar treatment products - Folur, Amalgerol and Litovit were set on the smaller plots (Factor B). The nontreated variant of each variety was used as control. The following basic panicle indices were studied: number of full and empty spikelet, panicle grain weight. All panicle elements were best developed in the favorable 2013 year. The Turkish cultivars formed the greatest number of grains with highest weight respectively, only under most favorable conditions (2013). The Italian cultivars, with the exception of Brio, behaved in a more adaptive manner throughout years with greater stress for the plants, especially during the flowering period (2014 and 2015). They formed grain from 2.5 to $2.9 \mathrm{~g}$ in 2014 and from 2.6 to $2.7 \mathrm{~g}$ in 2015. The application of foliar treatment products supported the plants to overcome stress and increased the grain weight.

Keywords: Rice (Oryza sativa L.), cultivars, panicle elements, foliar treatment products.

\section{INTRODUCTION}

According to Fageria et al. (1999) the main components of the rice yield are: number of panicles per unit area, number of spikelet in panicle, the fertility of the spikelet and the weight of the grain. It is considered that the number of the spikelet, usually, is one of the most volatile components, which is responsible for about $74 \%$ of the yield variations. On the other hand, Yoshida et al. (1976) express the opinion, that the fertility percentage of the spikelet and the grain weight, together, are responsible only for $26 \%$ of the changes in its value.

A significant effect of the genotype over the number of the grains per panicle is established by many authors. In the selection programs, targeted towards cultivate improvement, the big panicle and high

\footnotetext{
${ }^{1}$ Tonya Georgieva (corresponding author: tonia@au-plovdiv.bg), Ivanka Toromanova, Agricultural University - Plovdiv, BULGARIA.

Paper presented at the $8^{\text {th }}$ International Scientific Agricultural Symposium "AGROSYM 2017".

Notes: The authors declare that they have no conflicts of interest. Authorship Form signed online.
} 
production of biomass are considered as the major selection criteria (Khush, 2001), i.e. the panicle is the major field of work for the achievement of higher yields. As contrary to the above Jennings (1979) it is believed that the characteristics of the panicle just help in the determination of the elements of the productivity. The characteristic, which generally was used up to now for description of the quality of the rice was the weight of the grains (Zakaria et al., 2002; Morita et al., 2002).

The purpose of the study is to provide a comparative characteristics of perspective Turkish and Italian rice cultivars in relation to the formation of panicle basic elements and the influence of the foliar treatment products - Folur, Amalgerol and Litovit over them.

\section{MATERIAL AND METHODS}

In the period 2013-2015 a two-factor field experiment using the split plot method was carried out in the town of Saedinenie, Plovdiv region, Bulgaria. The basic studied factor (big plots) in the experiment was the genotype. Six introduced cultivars were tested - two of Turkish origin

(Osmanchik 97 and Gala) and four of Italian origin (Cameo, Lince, Puma and Brio), whereas Osmanchik 87 was used as the standard. The tested foliar treatment products (Folur, Amalgerol and Lithovit) were applied on the small plots. A non-treated control for each cultivar served for comparison. The experiment was set after rice as a fore-crop in four repetitions, with reported size of the harvested plot of $14.85 \mathrm{~m}^{2}$.

The statistical procession of the test data was made through SPSS V.9.0 for Microsoft Windows (1999). Variation proofs were indicated at significance level P 5\%.

The meteorological conditions for the vegetation year 2013 were favourable for rice growing (Fig. 1). The average temperatures from May till October were by $+0.2^{\circ} \mathrm{C}$ to $+3.8^{\circ} \mathrm{C}$ higher, compared with those in the long-term period. The latter contributed to: growth and development acceleration, formation of maximum productivity and shortening the vegetation period.

The agro conditions in 2014 were completely different from those in 2013. The average daily temperature results for the first two months of the vegetation period (May - June) showed, that at this stage rice was in less favourable conditions than the previous year. In the process of tillering and reaching full maturity, the registered temperatures were comparatively close to those in the long-term period. The average monthly rainfall for the whole vegetation period in 2014 was dramatically heavier compared to the long-term period and 2013 (Fig. 2). The registered heavy rains proved to be unfavourable for rice development as they changed the regulated water regime and microclimate in the rice enclosure. The amount of rainfall was lower only in August and the registered temperatures reached $35.6^{\circ} \mathrm{C}$, which did not facilitate normal rice flowering. 
The climatic situation in 2015 is generally very dynamic. It is characterized by favorable conditions in the first stages of rice development (similar to 2013), but the sharp increase in rainfall in the second half of the vegetation brings it closer to the unfavorable 2014.
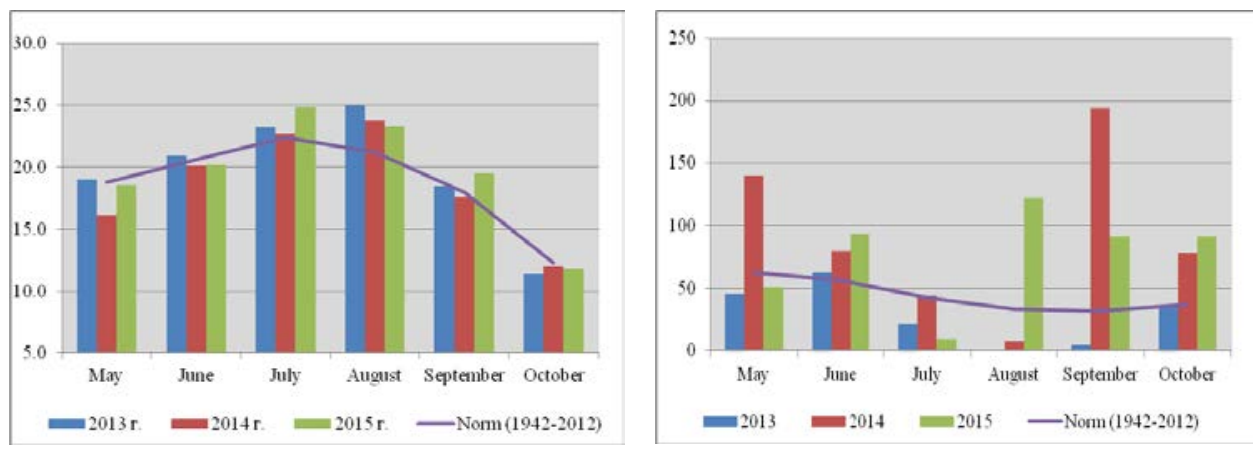

Fig. 1. Average monthly temperatures $\left({ }^{\circ} \mathrm{C}\right)$ and total sum of rainfall $\left(\mathrm{mm} / \mathrm{m}^{2}\right)$ for the research period, 2013-2015

\section{RESULTS AND DISCUSSION}

Number of full spikelet (grains) per panicle. Table 1 shows the data for number of full spikelet (grains) in a panicle, counted in the favorable year 2013. Significant differences are established between the tested cultivars. With Gala cultivar, in 2013, the highest number was formed (92.4), which exceed the control Osmanchik 97 by $14.8 \%$. All other cultivars were categorized within the boundaries of the control. Only with Lince cultivar, which during that year showed lowest productivity, their number is proven to be the lowest.

The tested products had positive influence over that indicator - with up to $5 \%$ increase compared to the non-treated variants, but that result cannot be statistically proven.

In year 2014 (Table 1) the categorical domination of all tested cultivars over the control Osmanchik 97, which has formed only 46.5 grains per panicle, was established. The differences were from 34 to $79 \%$ with different cultivars and these differences were statistically proven. The highest number of grains were present with the Italian cultivars Lince and Cameo (83.4 and 79.1 pieces) and the Turkish cultivar Gala (83.1 pieces). The serious differences of that indicator in one less favorable year showed specific cultivar sensitivity of the tested cultivars to stress factors.

The analysis of data from year 2015 confirmed and proved analogical dependence, established in the previous year, 2014. The two Turkish cultivars were with the lowest average values - of 60.6 pieces for cultivar Osmanchik 97 up to 60.9 pieces for cultivar Gala. The cultivar with the highest yield, Cameo, 
was with proven superiority in the number of grains per panicle (76.8 pieces), reaching over $26.6 \%$ compared to the control (Table 1 ).

The tested foliar treatment products had positive influence over this indicator during the experimental years, but the differences were within the range of 3 to 7 pieces per panicle $(4,4$ to $11.8 \%)$ and were not statistically proven.

Table 1. Effect of the cultivars and foliar treatment products on the number of grains per panicle for 2013, 2014 and 2015.

\begin{tabular}{|c|c|c|c|c|c|c|}
\hline \multirow{2}{*}{ Factor } & \multicolumn{6}{|c|}{ Variance analysis of the impact of factors on the number of grains per } \\
& \multicolumn{7}{|c|}{2013 panicle } & \multicolumn{2}{c|}{2014} & \multicolumn{2}{c|}{2015} \\
\cline { 2 - 7 } & Number & $\%$ & Number & $\%$ & Number & $\%$ \\
\cline { 2 - 7 } & \multicolumn{7}{|c|}{ Cultivar } \\
\hline Osmanchik 97 & $80,4 \mathrm{~b}$ & 100,0 & $46,5 \mathrm{c}$ & 100,0 & $60,6 \mathrm{~b}$ & 100,0 \\
\hline Gala & $92,4 \mathrm{a}$ & 114,8 & $83,1 \mathrm{a}$ & 178,8 & $60,9 \mathrm{~b}$ & 100,3 \\
\hline Linche & $69,8 \mathrm{c}$ & 86,8 & $83,4 \mathrm{a}$ & 179,4 & $75,8 \mathrm{a}$ & 125,0 \\
\hline Kameo & $75,0 \mathrm{bc}$ & 92,2 & $79,1 \mathrm{a}$ & 170,2 & $76,8 \mathrm{a}$ & 126,6 \\
\hline Puma & $82,4 \mathrm{~b}$ & 102,4 & $68,3 \mathrm{~b}$ & 146,9 & $67,4 \mathrm{~b}$ & 111,1 \\
\hline Brio & $79,0 \mathrm{~b}$ & 98,2 & $62,3 \mathrm{~b}$ & 134,1 & $64,2 \mathrm{~b}$ & 105,8 \\
\hline \multicolumn{7}{|c|}{ Foliar treatment product } \\
\hline Control & $77,1 \mathrm{a}$ & 100,0 & $66,7 \mathrm{a}$ & 100.0 & $64,1 \mathrm{a}$ & 100,0 \\
\hline Folur & $80,5 \mathrm{a}$ & 104,4 & $71,9 \mathrm{a}$ & 107,8 & $67,1 \mathrm{a}$ & 104,7 \\
\hline Amalgerol & $80,9 \mathrm{a}$ & 104,9 & $71,6 \mathrm{a}$ & 107,3 & $71,6 \mathrm{a}$ & 111,8 \\
\hline Litovit & $81.0 \mathrm{a}$ & 105,0 & $71,5 \mathrm{a}$ & 107,1 & $67,6 \mathrm{a}$ & 105,6 \\
\hline
\end{tabular}

Means followed by the same letter are not statistically different $(P<0,05)$ by Duncan's multiple range test.

The data, presented in Table 2, were analyzed for the performance of complex analysis of the influence of all tested factors (year, cultivar and product) during the entire period of the study.

The individual influence of the year over the number of grains in the panicle corresponded to the tendency, which is accounted in the productivity. A proven higher number of grains in the panicle was formed in year 2013, where their average number was 79.8.

When considering the influence of the cultivar over the number of the grains per panicle, it was established that all of the tested cultivars surpass the control Osmanchik 97 and the differences vary up to 26\%. Gala, Lince and Cameo were distinguished as cultivars with highest number of grains per panicle during the three test years (up to 78 pieces).

Analyzing the data of the influence of the tested foliar treatment products over the grains, it was established that there were no statistically proven differences, but such were observed to up to $7.8 \%$ in favor of the most effective product - Amalgerol.

Weight of the full spikelet (grains) in panicle. The most important indicator, directly related to the yield is the weight of the grains, formed in a 
panicle. The observations, performed in year 2013 and the tracked influence of the cultivar proved (Table 3) that the two Turkish cultivars, Osmanchik 97 and Gala, formed the highest weight of grains in panicle and all other cultivars fall below their values. The treatment with foliar products showed an effect compared to the control cultivar, equal to $12.3-13.9 \%$ in favor of Litovit and Amalgerol and a smaller effect (3.2\%) with Folur.

Table 2. Impact of main factors (variance analysis) on number of grains per panicle in rice

\begin{tabular}{|c|c|c|c|c|c|c|c|c|c|c|c|c|}
\hline \multicolumn{10}{|c|}{ Number of grains per panicle (GP) in rice and Duncan's test (DT) } \\
\hline & GP & DT & $\%$ & \multicolumn{3}{|c|}{ GP } & DT & $\%$ & & GP & DT & $\%$ \\
\hline \multicolumn{3}{|c|}{ Year effect } & \multicolumn{3}{|c|}{ Cultivar effect } & \multicolumn{3}{|c|}{ Foliar treatment effect } \\
\hline & & & & Os. 97 & 62.5 & c & 100.0 & & & & \\
\hline 2013 & 79.8 & a & 100.0 & Gala & 78.8 & a & 126.0 & Contr. & 69.3 & a & 100.0 \\
\hline 2014 & 70.4 & b & 88.2 & Linche & 76.3 & a & 122.1 & Folur & 73.2 & a & 105.6 \\
\hline 2015 & 67.6 & b & 84.7 & Kameo & 77.0 & a & 123.1 & Amal. & 74.7 & a & 107.8 \\
\hline & & & & Puma & 72.7 & ab & 116.3 & Litovit & 73.4 & a & 105.9 \\
\hline & & & & Brio & 68.5 & abc & 109.6 & & & & \\
\hline
\end{tabular}

Means followed by the same letter are not statistically different $(P<0,05)$ by Duncan's multiple range test

The cultivars Gala, Lince, Cameo and Puma had values of $2.5 \mathrm{~g}$ up to $2.8 \mathrm{~g}$ 2014 (Table 3), which significantly surpassed the control cultivar Osmanchik 97 with more than $1 \mathrm{~g}$ per panicle. Surpassing of the weight of the formed grains in panicle was observed with the plots, treated with Folur, Amalgerol and Litovit, but with a lower extend (2.3 to 9.5\%) compared to the previous year.

For 2015, considering the similar agro-meteorological conditions with year 2014, the statistical analysis showed close tendencies. The difference was observed in the fact that Gala (2.0 g), fall in the category of Osmanchik 97. The above corresponded to our conclusions, that the Turkish cultivars perform with good productivity only in favorable year, in terms of agro-meteorological conditions, as was year 2013. The increase of the weight of the grains per panicle was also observed as a result of the usage of the products Amalgerol and Litovit.

The data for the complex influence of the factors year, cultivar and tested preparation over the weight of the grains per panicle, in the period of the threeyears test are presented in Table 4.

In relation to the influence of the year over that indicator, it was statistically proven that the highest weight was observed for the cultivars in year 2013.

The data about the influence of the cultivar over the weight of the grains per panicle clearly showed that all tested cultivars surpass the control. The cultivars were most positively influenced by Amalgerol - with $12 \%$ increase, followed by Folur and Litovit - about 7\%. 
Table 3. Effect of the cultivars and foliar treatment products on the grain weight per panicle

\begin{tabular}{|c|c|c|c|c|c|c|}
\hline \multirow{2}{*}{ Factor } & \multicolumn{6}{|c|}{ Variance analysis of the impact of factors on the grain weight per panicle } \\
\cline { 2 - 7 } & \multicolumn{2}{|c|}{2013} & \multicolumn{2}{c|}{2014} & \multicolumn{2}{c|}{2015} \\
\cline { 2 - 7 } & $\mathrm{g}$ & $\%$ & $\mathrm{~g}$ & $\%$ & $\mathrm{~g}$ & $\%$ \\
\hline Osmanchik 97 & $3.1 \mathrm{a}$ & 100.0 & $1.6 \mathrm{~b}$ & 100.0 & $2.0 \mathrm{c}$ & 100.0 \\
\hline Gala & $3.1 \mathrm{a}$ & 99.4 & $2.6 \mathrm{a}$ & 161.0 & $2.0 \mathrm{c}$ & 101.5 \\
\hline Linche & $2.4 \mathrm{c}$ & 75.4 & $2.7 \mathrm{a}$ & 167.1 & $2.5 \mathrm{a}$ & 130.3 \\
\hline Kameo & $2.5 \mathrm{c}$ & 78.3 & $2.8 \mathrm{a}$ & 170,1 & $2.8 \mathrm{a}$ & 145.6 \\
\hline Puma & $2.8 \mathrm{~b}$ & 87.9 & $2.5 \mathrm{a}$ & 149.4 & $2.3 \mathrm{~b}$ & 117.4 \\
\hline Brio & $2.4 \mathrm{c}$ & 77.0 & $1.6 \mathrm{~b}$ & 95.7 & $2.1 \mathrm{~b}$ & 109.2 \\
\hline & & Foliar treatment product & & \\
\hline Control & $2.5 \mathrm{~b}$ & 100.0 & $2.2 \mathrm{a}$ & 100.0 & $2.2 \mathrm{~b}$ & 100.0 \\
\hline Folur & $2.6 \mathrm{ab}$ & 103.2 & $2.4 \mathrm{a}$ & 109.5 & $2.3 \mathrm{ab}$ & 104.2 \\
\hline Amalgerol & $2.9 \mathrm{a}$ & 113.9 & $2.3 \mathrm{a}$ & 105.4 & $2.5 \mathrm{a}$ & 114.4 \\
\hline Litovit & $2.8 \mathrm{a}$ & 112.3 & $2.3 \mathrm{a}$ & 102.3 & $2.3 \mathrm{a}$ & 105.1 \\
\hline
\end{tabular}

Means followed by the same letter are not statistically different $(P<0,05)$ by Duncan's multiple range test.

Number of empty (sterile) spikelet in a panicle. The conditions, in which the panicle is formed are determinant for the achievement of the potential of the observed biometric parameters. The high percentage of empty spikelet can be due to the low solar radiation 3 weeks before and after the panicle emergence. There are also genotype differences. The cloudy and rainy weather in the period of accumulation of plastic substances has negative effect over the carbohydrates synthesis and their accumulation in the grain (Bradbrook, 2012).

The number of empty spikelet per panicle is a function, first of all, of the unfavorable agro-meteorological conditions during the blossoming period and growing of the grains.

The values accounted in year 2013 (Table 5) showed insignificant loss of the potential of the panicle due to empty spikelet (5.4 pieces). This fact is in absolute unison with the panicles rich in grains and the high yield during that year. But in years 2014 and 2015, the panicles had about 15 pieces of empty spikelet. We relate the high number to the insufficient sunshine and abundant rainfalls in the critical phases in those years.

The highest number of empty spikelet per panicle average for the period was observed with Osmanchik 97 (17.15 pieces) and Brio (15.70 pieces). The impact of the tested products is insignificant. 
Table 4. Impact of main factors (variance analysis) on grain weight per panicle in rice

\begin{tabular}{|c|c|c|c|c|c|c|c|c|c|c|c|}
\hline \multicolumn{12}{|c|}{ Grain weight per panicle (GW in g) in rice and Duncan's test (DT) } \\
\hline & GW & DT & $\%$ & & GW & DT & $\%$ & & GW & DT & $\%$ \\
\hline \multicolumn{4}{|c|}{ Year effect } & \multicolumn{4}{|c|}{ Cultivar effect } & \multicolumn{4}{|c|}{ Foliar treatment effect } \\
\hline & & & & Os. 97 & 2.1 & b & 100.0 & & & & \\
\hline 2013 & 2.7 & $\mathrm{a}$ & 100.0 & Gala & 2.6 & $\mathrm{a}$ & 122.9 & Contr. & 2.3 & $\mathrm{~A}$ & 100.0 \\
\hline 2014 & 2.4 & $\mathrm{~b}$ & 88.9 & Linche & 2.6 & $\mathrm{a}$ & 121.4 & Folur & 2.5 & A & 107.3 \\
\hline 2015 & 2.3 & $\mathrm{~b}$ & 85.2 & Kameo & 2.7 & $\mathrm{a}$ & 127.6 & Amal. & 2.6 & A & 112.0 \\
\hline & & & & Puma & 2.5 & $\mathrm{a}$ & 119.0 & Litovit & 2.5 & A & 106.9 \\
\hline & & & & Brio & 2.5 & $\mathrm{a}$ & 118.6 & & & & \\
\hline
\end{tabular}

Means followed by the same letter are not statistically different $(P<0,05)$ by Duncan's multiple range test

Table 5. Impact of main factors (variance analysis) on number of empty spikelet per panicle

\begin{tabular}{|c|c|c|c|c|c|c|c|c|c|c|c|}
\hline \multicolumn{12}{|c|}{ Number of empty spikelet per panicle (ESN) in rice and Duncan's test (DT) } \\
\hline & ESN & DT & $\%$ & & ESN & DT & $\%$ & & ESN & DT & $\%$ \\
\hline \multicolumn{4}{|c|}{ Year effect } & \multicolumn{4}{|c|}{ Cultivar effect } & \multicolumn{4}{|c|}{ Foliar treatment effect } \\
\hline & & & & Os. 97 & 17.2 & $\mathrm{a}$ & 100.0 & & & & \\
\hline 2013 & 5.4 & $\mathrm{~b}$ & 100.0 & Gala & 10.4 & $\mathrm{~b}$ & 60.4 & Contr. & 11.1 & A & 100.0 \\
\hline 2014 & 14.8 & $\mathrm{a}$ & 272.0 & Linche & 8.3 & $\mathrm{~b}$ & 48.1 & Folur & 12.2 & A & 110.0 \\
\hline \multirow[t]{3}{*}{2015} & 15.0 & $\mathrm{a}$ & 275.3 & Kameo & 7.8 & $\mathrm{~b}$ & 45.2 & Amal. & 11.4 & A & 102.1 \\
\hline & & & & Puma & 11.0 & $\mathrm{~b}$ & 64.3 & Litovit & 12.2 & A & 109.3 \\
\hline & & & & Brio & 15.7 & $\mathrm{a}$ & 91.5 & & & & \\
\hline
\end{tabular}

Means followed by the same letter are not statistically different $(P<0,05)$ by Duncan's multiple range test

\section{CONCLUSIONS}

The number of formed grains per panicle is within the limits from 67 to 79 pieces and is proven to be influenced by the conditions during the year. All tested cultivars surpass the control Osmanchik 97 with differences up to 26\%. Gala, Lince and Cameo are distinguished as cultivars with highest number of grains (up to 78 pieces). Amalgerol is most effective and it increases the number of grtain per panicle with almost $8 \%$.

The weight of the grains per panicle is highly influenced (with differences from 11 to 15\%) by the conditions during the years. The cultivar Cameo is distinguished with a weight of the grains of $2.7 \mathrm{~g}$ (28\% more compared to the control). Amalgerol increases the weight with $12 \%$ and Folur and Litovit - with about $7 \%$.

The number of empty spikelet per panicle is most significantly dependent on the agro-meteorological conditions during the years and the differences can reach up to $175 \%$. All tested cultivars (with the exception of Brio) form panicles with smaller number of empty spikelet compared to Osmanchik 97. 


\section{REFERENCES}

Fageria, N. K., \& Baligar, V. C. (1999). Yield and yield components of lowland rice as influenced by timing of nitrogen fertilization. Journal of Plant Nutrition, 22(1), 2332.

SAS Institute Inc.1999. SAS Procedures Guide, SPSS for Microsoft Windows, V.9, 4 edition.

Yoshida, S., \& Parao, F. T. (1976). Climatic influence on yield and yield components of lowland rice in the tropics. Climate and rice, 471-494.

Jennings, C. R., Coffman, W. R., \& Kauffman, H. E. (1979). Rice development. Los Baños (Philippines): International Rice Research Institute.

Khush, G. S. (2001). Challenges for meeting the global food and nutrient needs in the new millennium. Proceedings of the Nutrition Society, 60(01), 15-26.

Morita, S., Shiratsuchi, H., Takanashi, J. I., \& Fujita, K. (2002). Effect of High Temperature on Ripening in Rice Plants-Comparison of the effects of high night temperatures and high day temperatures. Japanese Journal of Crop Science, 71(1), 102-109.

Zakaria, S., Matsuda, T., Tajima, S., \& Nitta, Y. (2002). Effect of high temperature at ripening stage on the reserve accumulation in seed in some rice cultivars. Plant production science, 5(2), 160-168. 